\title{
Antibody therapy in renal cell carcinoma
}

\author{
Egbert Oosterwijk - Otto C. Boerman · \\ Wim J. C. Oyen · Lloyd J. Old · Peter F. A. Mulders
}

Received: 3 December 2007 / Accepted: 8 January 2008/Published online: 1 February 2008

(C) The Author(s) 2008

\begin{abstract}
The treatment of metastasized renal cell carcinoma (RCC) still represents a formidable challenge, despite the development of small molecule, tyrosine kinase inhibitors (TKI) that have made a major impact on the disease. Although the percentage of patients achieving a partial response or stabilization of disease has been impressive, these effects are mostly non-durable. Additionally, drug-related side effects can be quite severe. Alternative treatment modalities might be monoclonal antibodies (mAbs). mAbs against RCC-associated antigens have been developed and have shown promise. Additionally, current efforts focus on Bevacizumab that recognizes vascular endothelial growth factor (VEGF). VEGF overexpression in RCC provides the opportunity to inhibit this proangiogenic pathway. Also with Bevacizumab, promising results have been obtained, particularly in combination with other treatment modalities. It is likely that mAbs, either as single agents or in combination with other agents,
\end{abstract}

E. Oosterwijk $(\bowtie)$

267 Experimental Urology,

University Medical Center St Radboud,

Geert Grooteplein 26-28, 6525 GA Nijmegen,

The Netherlands

e-mail: e.oosterwijk@uro.umcn.nl

O. C. Boerman · W. J. C. Oyen

444 Nuclear Medicine, University Medical Center St Radboud, Geert Grooteplein Zuid 8, 6525 GA Nijmegen, The Netherlands

\section{J. Old}

Ludwig Institute for Cancer Research, 605 Third Avenue, New York, NY 10158, USA

P. F. A. Mulders

659 Urology, University Medical Center St Radboud,

Geert Grooteplein Zuid 10, 6525 GA Nijmegen,

The Netherlands may become useful additions to the armamentarium to diagnose and treat RCC.

Keywords Monoclonal antibody $\cdot$ Renal $\cdot$ RCC . VEGF · G250 · CAIX · Therapy

\section{Introduction}

The hypothesis by Ehrlich in early 1900s that malignant cells express unique structures that can be used to guide cytotoxic therapy to tumors [1] followed by the development of the hybridoma technique by Kohler and Milstein almost 70 years later [2] has led to the development of anticancer reagents with unique characteristics. One of the most distinguishing factors is the possibility to select monoclonal antibodies (mAbs) recognizing target molecules with very restricted expression in normal tissues. To date, tumor-specific antigens (antigens expressed on all tumor cells of a particular tumor type not expressed by normal cells) have not been identified. The members of the so-called cancer-testis family do exhibit highly tissuerestricted expression, but are considered promising target molecules for cancer vaccines, less for antibody therapy, particularly in view of the extreme intra- and inter-tumor heterogeneity [3].

Similar to other malignancies, monoclonal antibodies (mAbs) targeting renal cell carcinoma (RCC) associated molecules were developed without understanding the molecular events underlying RCC [4-8]. The increased understanding of molecular events important in the carcinogenesis of RCC led to the recognition that these aberrations can be used to target RCC. Specifically, aberrant von Hippel-Lindau (VHL) gene expression has been identified as a general event in clear cell RCC (ccRCC) [9], 
which represents $80-85 \%$ of localized cases and $90-95 \%$ of metastatic RCC (mRCC). The loss of a functional VHL gene product leads to accumulation of the transcription factor HIF- $1 \alpha$ that is an obligatory element for the transcription of several genes. This includes vascular endothelial growth factor (VEGF) and carbonic anhydrase 9 (CA9), targets for which most clinical experience with $\mathrm{mAbs}$ in RCC has been generated (Bevacizumab and G250, respectively).

The rationale and effects of Bevacizumab and G250directed therapy are fundamentally different: Bevacizumab treatment leads to VEGF-depletion and consequently to diminished neovascularization followed by tumor cell death, mainly due to loss of vascularization. In contrast, G250 treatment targets the cell surface of RCC cells where it must exert toxic effects. Both approaches have advantages and disadvantages. Bevacizumab treatment has the advantage that VEGF depletion can be achieved in the circulation, and homing to all tumor vessels is not necessary. However, other regulatory pathways can also lead to neovascularization and small, non-vascularized tumor loci will not be affected. G250 treatment has the advantage that RCC cells can be targeted, irrespective of tumor size. However, in view of the generally poor perfusion rate and high interstitial fluid pressure in RCC, deep penetration of tumors may be difficult. Also, since G250-binding alone does not confer a lytic signal to RCC cells, tumor cell kill requires effector cells or coupling of G250 to toxic agents.

\section{Bevacizumab}

Bevacizumab is a humanized mAb against VEGF that binds and neutralizes all of the major isoforms of VEGF [10]. This prevents VEGF from interacting with its receptors and activation of downstream signaling pathways. This mode of action is thought to lead to regression of existing microvasculature, normalization of mature vasculature, and inhibition of the production of new vasculature [11]. Whether all these effects are true for RCC is unclear at the moment.

Significant protein dose levels are needed to maintain sufficiently high Bevacizumab levels to trap VEFG, the target of Bevacizumab. The first Bevacizumab trial in metastatic RCC (mRCC) patients addressed whether Bevacizumab treatment could lengthen the time to progression of disease and the response rate [12]. Survival was a secondary end point. In this randomized phase II trial, 116 patients with metastatic, refractory clear cell RCC were randomized to placebo, low-dose $(3 \mathrm{mg} / \mathrm{kg})$ Bevacizumab, or high-dose $(10 \mathrm{mg} / \mathrm{kg})$ Bevacizumab given intravenously every 2 weeks. All patients had prior disease progression while on systemic treatment; the vast majority had received prior interleukine-2. Patients with disease progression on placebo crossed over to receive low-dose Bevacizumab. Bevacizumab treatment resulted in a significant prolongation of the time to progression of disease in the high-dose antibody group (4.8 months as compared with 2.5 months). Possibly, the low-protein dose was inadequate to sufficiently deplete circulating VEGF levels in-between injections, explaining the poor outcome in this group. The study was inadequately powered to show a significant difference in overall survival between groups. Based on this encouraging result, Bevacizumab has been combined with other treatment modalities to augment the therapeutic index.

\section{Bevacizumab in combination}

The AVOREN trial investigated the effects of standard therapy of interferon alfa-2a plus placebo or interferon alfa-2a plus Bevacizumab, administered every 2 weeks at a dose of $10 \mathrm{mg} / \mathrm{kg}$ [13]. In this randomized, double blind phase III trial, 649 patients with first-line mRCC were enrolled. The primary analysis endpoint was assessment of improvement in progression-free survival (PFS), defined as the length of time the tumor did not grow or patient death did not occur. Other endpoints of the study included overall survival, time to progression, time to treatment failure, overall response rate, and safety profile. The addition of Bevacizumab to IFN- $\alpha 2$ a significantly increased PFS (10.2 vs. 5.4 months) and objective tumor response rate (30.6 vs. $12.4 \% ; P<0.0001)$. Additionally, the combination treatment showed a trend toward improved overall survival $(P=0.0670)$, which leads to the conclusion that the combination of Bevacizumab with IFN- $\alpha 2 \mathrm{a}$ is superior to either of the single treatment regimens in $\mathrm{mRCC}$. The working mechanism explaining the superiority of this combination treatment has not been defined yet, but most likely the superiority is the net effect of the reduction of the immunosuppressive effects due to decreased VEGF levels combined with the immunomodulatory effects of IFN.

Considering that the epidermal growth factor receptor (EGFR) is also overexpressed in RCC, a multicenter, phase II study evaluated the addition of erlotinib (Tarceva), an EGFR inhibitor, to Bevacizumab in metastatic RCC patients [14]. Treatment consisted of $10 \mathrm{mg} / \mathrm{kg} \mathrm{Bev-}$ acizumab given intravenously every 2 weeks and $150 \mathrm{mg}$ erlotinib given orally each day. With 15 (25\%) patients showing objective responses, and an additional 36 patients $(61 \%)$ with stable disease after 8 weeks of treatment, a randomized phase II trial was performed evaluating Bevacizumab + placebo versus Bevacizumab + erlotinib. Disappointingly, identical response rates and PFS rates for 
the two arms were observed [15], and it is doubtful that EGFR-targeting is of any benefit.

The effect of Bevacizumab and low-dose interleukine-2 (IL-2) in mRCC was evaluated in a phase II trial in previously untreated, good and intermediate risk, mRCC patients. Patients received 8-week cycles of IL-2 (250,000 U/kg per day s.c. Day 1-5 during week 1 and $125,000 \mathrm{U} / \mathrm{kg}$ per day s.c. Day $1-5$ during weeks 2-6, followed by a 2 week break), and Bevacizumab $10 \mathrm{mg} / \mathrm{kg}$ was administered i.v. every 2 weeks starting on day- 14 . With 16 of the planned 35 patients enrolled, and 11 evaluable patients for response, 1 partial response (PR) and 3 stable disease (SD) lasting $>3$ months were observed [16]. All patients with SD demonstrated some degree of tumor shrinkage. Similar to the working mechanism of the Bevacizumab/IFN combination, the anti-tumor effects are possibly the result of the reduction of the immunosuppressive effects due to decreased VEGF levels combined with the general immune activating effects of IL-2. Interestingly, treated patients demonstrated an increase in the number of regulatory $\mathrm{T}$ cells without effect on $\mathrm{DC}$ activation. Larger, randomized studies will be necessary to address the value of this combination treatment.

In a phase I trial, Bevacizumab has also been combined with sunitinib (Sutent ${ }^{\circledR}$ ), a tyrosine kinase inhibitor, with the hypothesis that this combination may increase antitumor efficacy by maximizing inhibition of the VEGF pathway. The Bevacizumab dose was kept constant $(10 \mathrm{mg} / \mathrm{kg})$ while the sunitinib dose was escalated starting at $25 \mathrm{mg}$ (escalation with $12.5 \mathrm{mg}$ increments). Of 13 patients evaluated for best response, 4 had partial responses, 7 had stable disease, and 2 had PD [17].

Similarly, the combination of Bevacizumab and the mTOR inhibitor CCI-779 (Temsirolimus ${ }^{\circledR}$ ) has been investigated. Patients received $25 \mathrm{mg} /$ week Temsirolimus and 5 or $10 \mathrm{mg} / \mathrm{kg}$ Bevacizumab. In 12 evaluable patients, 7 PR and 3 SD were observed [18]. The encouraging results certainly deserve further testing of these combinations in phase II trials.

\section{Monoclonal antibody G250}

G250 is a mAb against CA9, a molecule which is ubiquitously expressed in ccRCC [19]. CA9 expression in nonccRCC has also been documented, and there, it is most likely a reflection of (sustained) hypoxia [20]. Clinical efforts with mAb G250 in RCC have focused on radioimmunotherapy and passive immunotherapy. This mAb was described as a mAb recognizing an RCC-associated antigen, absent in normal kidney and homogeneously expressed in most RCC [4], most notably clear cell RCC [19]. In 2000, the G250 antigen molecule was identified and shown to be CA9 [21]. The molecular characterization allowed transcriptional regulation studies that revealed a strict dependence of G250 expression on HIF-1 $\alpha$ [22]. Thus, the molecular mechanism responsible for CAIX expression in ccRCC is similar to VEGF, namely due to non-functional VHL protein leading to HIF- $1 \alpha$ accumulation and gene expression.

The first clinical trials with mAbG250 were already performed and published before the molecular characterization of G250 antigen was achieved. The combined data from the immunohistochemical tissue distribution, animal experiments and ex vivo perfusion of tumor bearing kidneys had provided sufficient evidence to initiate a biopsybased phase I protein dose escalation trial with murine mAbG250. The rationale of G250-directed therapy obviously differs from Bevacizumab: Bevacizumab treatment leads to VEGF-depletion and consequently to diminished neovascularization whereas G250 treatment targets RCC cells directly. This first mAbG250 clinical trial demonstrated various pivotal aspects: most notably, virtually no uptake in other tissues resulting in excellent tumor visualization, and very high tumor uptake [23].

The G250 antibody uptake that was observed was up to 10 -fold higher than any other mAb uptake in solid tumors, which led to the design of a phase I/II radioimmunotherapy (RIT) trial with murine mAbG250. RIT led to stabilization of disease in 17 of 33 patients, with tumor shrinkage observed in two patients. Transient liver toxicity was observed, quite likely the result of mAbG250 liver uptake, although there was no correlation between the amount of ${ }^{131}$ I administered or hepatic absorbed radiation dose and the extent and nature of hepatic toxicity [24].

Because the murine G250 antibody was highly immunogenic, restricting multiple injections, mAbG250 was chimerized. The results of the phase I protein dose escalation trial with chimeric G250 (cG250) basically duplicated the results from the murine G250 trial: virtually no uptake in other tissues resulting in excellent tumor visualization, and very high tumor uptake. The half-life of the antibody was extended, as was to be expected, but, more importantly, the chimerized from of G250 was almost immunosilent [25]. Thus, multiple injections became possible. Various phase I and phase II trials have been performed with cG250 aimed at therapeutic intervention. Based on the very high uptake levels, several RIT trials were performed. In the first phase I trial with ${ }^{131} \mathrm{I}-\mathrm{cG} 250$, one patient showed a partial response ( $>9$ months) [26] which set the stage for phase II RIT trials in metastatic RCC patients. RIT studies with single high dose ${ }^{131} \mathrm{I}-\mathrm{G} 250$, rapid fractionated dose ${ }^{131} \mathrm{I}-\mathrm{G} 250$ [27], and sequential high dose ${ }^{131}$ I-G250 [28] have resulted in only occasional therapeutic responses, although dosimetric analyses suggest that tumor-sterilizing levels can be reached. Even two 
sequential high-dose treatments with ${ }^{131} \mathrm{I}-\mathrm{G} 250$ did not result in objective responses, but in stabilization of previously progressive disease in a few patients. RIT with G250 has been accompanied by bone marrow toxicity similar to $\mathrm{mAb}$ RIT in other tumor types and considering the minimal benefit, ${ }^{131}$ I-based RIT with cG250 have been abandoned. Since RCC is a radiotherapy resistant tumor, possibly even higher radiation doses are necessary to achieve tumorsterilizing levels. Current G250 RIT efforts are directed to 177-lutetium and 90-yttrium labeled G250. It is hypothesized that the use of more powerful radionuclides that are also better retained in the tumor cells may lead to clinical responses. Animal experiments have demonstrated the superiority of ${ }^{177} \mathrm{Lu}$ - and ${ }^{90} \mathrm{Y}$-labeled G250 over ${ }^{131} \mathrm{I}-\mathrm{G} 250$ [29]. Importantly, stabilization of previously progressive disease has been observed in almost all ${ }^{177} \mathrm{Lu}-\mathrm{G} 250$ treated patients, although the maximum tolerable ${ }^{177} \mathrm{Lu}$ dose has not been achieved. Dosimetric analyses of the first patients treated with ${ }^{177} \mathrm{Lu}-\mathrm{G} 250$ suggest that indeed tumor-sterilizing levels may be achieved. Figure 1 illustrates targeting of ${ }^{177} \mathrm{Lu}-\mathrm{G} 250$ in a patient with metastatic renal cancer.

In view of the obvious tumor-specific accumulation of cG250, passive immunotherapy of RCC patients has also been studied extensively. In vitro mAbG250 can elicit antibody-dependent cellular cytotoxicity (ADCC), which can be enhanced by low dose IL-2 [30]. Various (nonrandomized) clinical trials have now been completed with cG250 alone, and in combination with IL2 or interferon $[31,32]$. Thus far, these treatments appear to lead to extended survival time. The apparent clinical benefit appears to be quite substantial with a documented median survival of 22 months in patients with metastatic RCC who have progressive disease at study entry. Nevertheless, it is difficult to judge the value of this treatment. Clearly, randomized trials are necessary to unequivocally demonstrate whether passive immunotherapy with cG250 is of benefit for metastatic RCC patients.

The largest trial, which is currently ongoing, is the adjuvant ARISER trial (adjuvant Rencarex immunotherapy phase III trial to study efficacy in nonmetastatic renal cell carcinoma). In this phase III randomized, double blind, placebo-controlled trial, patients with ECOG performance status of 0 with completely resected primary clear cell RCC and no evidence of remaining local or distant disease, are treated. The study is designed to detect a significant difference between the two treatment arms with respect to disease-free survival; patients will be followed-up longterm to determine overall survival statistics.

Recently, the potential utility of mAbG250 as a diagnostic imaging agent was investigated [33]. The excellent imaging capability had been noted in almost all patients, but this line of research was not pursued mainly because detection of suspect renal masses and occult metastatic

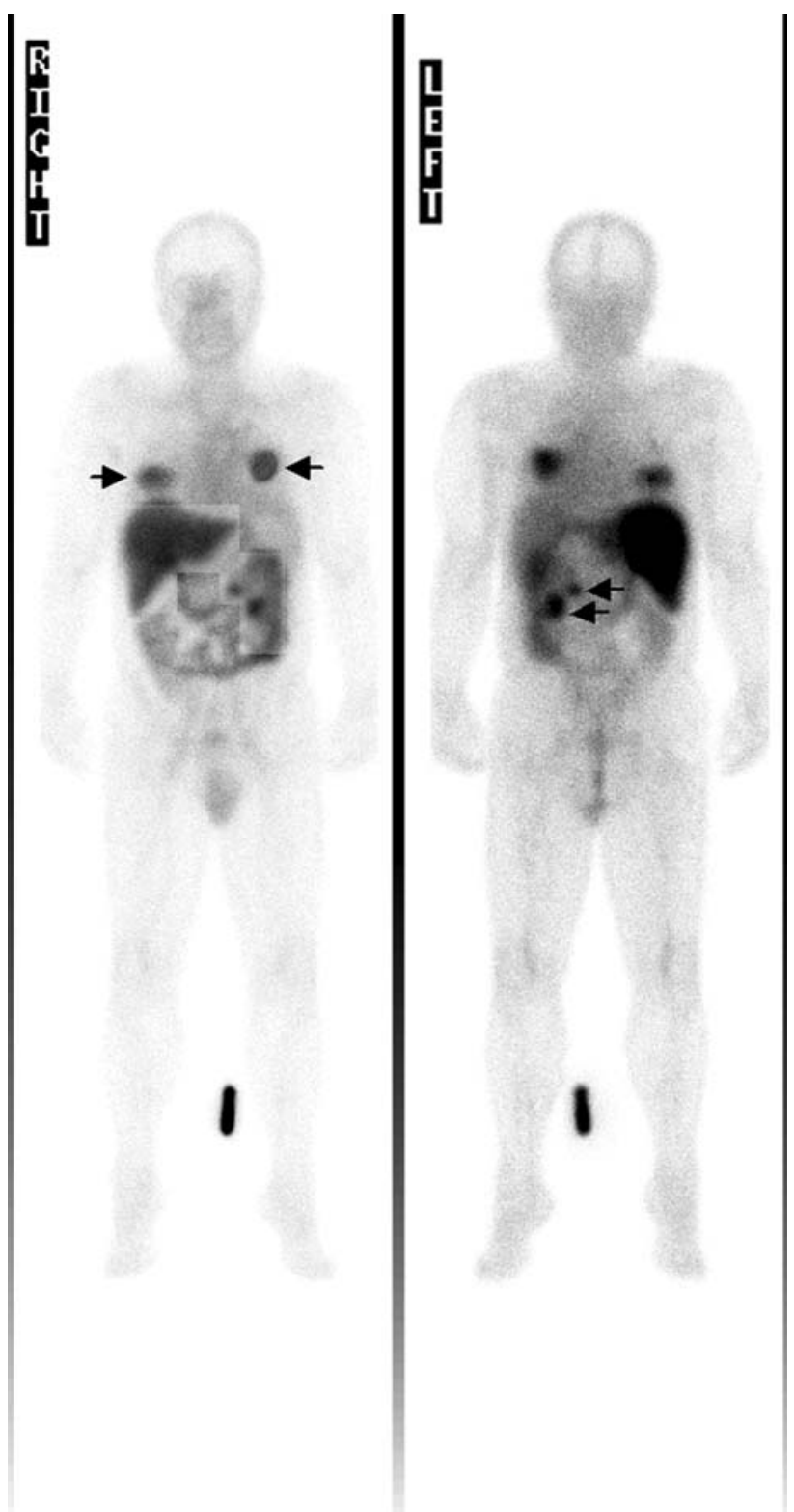

Fig. 1 Anterior (left) and posterior (right) whole body scans acquired 7 days post-injection of patient injected with ${ }^{177} \mathrm{Lu}-\mathrm{cG} 250$. Please note high uptake in both pulmonary lesions and in contralateral kidney lesions. Uptake in liver is due to the conjugation methodology and is not related to G250 antigen expression

RCC was not deemed advantageous. Additionally, treatment modalities for metastasized RCC were poor, and, therefore, efforts focused on treatment. However, with a steady increase of incidentally discovered renal masses and new therapeutic modalities becoming available, imaging might become of importance to distinguish more potentially malignant tumours from less aggressive variants. In the first prospective clinical trial with ${ }^{124} \mathrm{I}$-labeled cG250, a very high specificity and sensitivity to identify ccRCC in patients with suspect renal masses was demonstrated, a clear indication of the potential clinical utility. Whether 
this imaging modality can be used to follow therapy effects remains to be determined.

In conclusion, it is reasonable to assume that Bevacizumab and G250 monoclonal antibodies either as single agents or in combination with other agents may become useful additions to the armamentarium to diagnose and treat (cc)RCC. Several trials evaluating the combination of G250 or Bevacizumab with registered RCC treatments are currently in progress and will further define the role of these mAbs in RCC.

Conflict of interest statement There is no conflict of interest.

Open Access This article is distributed under the terms of the Creative Commons Attribution Noncommercial License which permits any noncommercial use, distribution, and reproduction in any medium, provided the original author(s) and source are credited.

\section{References}

1. Ehrlich P (1906) Collected studies on immunology. John Wiley, New York. Ref type: generic

2. Kohler G, Milstein C (1975) Continuous cultures of fused cells secreting antibody of predefined specificity. Nature 256(5517):495-497

3. Scanlan MJ, Simpson AJ, Old LJ (2004) The cancer/testis genes: review, standardization, and commentary. Cancer Immun 4:1

4. Oosterwijk E, Ruiter DJ, Hoedemaeker PJ, Pauwels EK, Jonas U, Zwartendijk J et al (1986) Monoclonal antibody G 250 recognizes a determinant present in renal-cell carcinoma and absent from normal kidney. Int J Cancer 38(4):489-494

5. Finstad CL, Cordon-Cardo C, Bander NH, Whitmore WF, Melamed MR, Old LJ (1985) Specificity analysis of mouse monoclonal antibodies defining cell surface antigens of human renal cancer. Proc Natl Acad Sci USA 82(9):2955-2959

6. Bander NH, Finstad CL, Cordon-Cardo C, Ramsawak RD, Vaughan ED Jr, Whitmore WF Jr et al (1989) Analysis of a mouse monoclonal antibody that reacts with a specific region of the human proximal tubule and subsets renal cell carcinomas. Cancer Res 49(23):6774-6780

7. Vessella RL, Moon TD, Chiou RK, Nowak JA, Arfman EW, Palme DF et al (1985) Monoclonal antibodies to human renal cell carcinoma: recognition of shared and restricted tissue antigens. Cancer Res 45(12 Pt 1):6131-6139

8. Oosterwijk E, Ruiter DJ, Wakka JC, Huiskens-van der Meij JW, Jonas U, Fleuren GJ et al (1986) Immunohistochemical analysis of monoclonal antibodies to renal antigens. Application in the diagnosis of renal cell carcinoma. Am J Pathol 123(2):301-309

9. Gnarra JR, Lerman MI, Zbar B, Linehan WM (1995) Genetics of renal-cell carcinoma and evidence for a critical role for von Hippel-Lindau in renal tumorigenesis. Semin Oncol 22(1):3-8

10. Presta LG, Chen H, O'Connor SJ, Chisholm V, Meng YG, Krummen L et al (1997) Humanization of an anti-vascular endothelial growth factor monoclonal antibody for the therapy of solid tumors and other disorders. Cancer Res 57(20):4593-4599

11. Jain RK (2005) Normalization of tumor vasculature: an emerging concept in antiangiogenic therapy. Science 307(5706):58-62

12. Yang JC, Haworth L, Sherry RM, Hwu P, Schwartzentruber DJ, Topalian SL et al (2003) A randomized trial of bevacizumab, an anti-vascular endothelial growth factor antibody, for metastatic renal cancer. N Engl J Med 349(5):427-434
13. Escudier B, Koralewski A, Pluzanska A, Ravaud S, Bracarda C, Szczylik C et al. (2007) A randomized, controlled, double-blind phase III study (AVOREN) of bevacizumab/interferon-a2a vs placebo/interferon-a2a as first-line therapy in metastatic renal cell carcinoma. J Clin Oncol, 2007 ASCO annual meeting proceedings part 1, vol 25, no $18 \mathrm{~S}$ (June Supplement):3

14. Hainsworth JD, Sosman JA, Spigel DR, Edwards DL, Baughman C, Greco A (2005) Treatment of metastatic renal cell carcinoma with a combination of bevacizumab and erlotinib. J Clin Oncol 23(31):7889-7896

15. Bukowski RM, Kabbinavar F, Figlin RA, Flaherty K, Srinivas S, Vaishampayan U et al (2006) Bevacizumab with or without erlotinib in metastatic renal cell carcinoma (RCC). J Clin Oncol, 2006 ASCO annual meeting proceedings part I, vol 24 , no $18 \mathrm{~S}$ (June 20 Supplement):4523

16. Garcia JA, Rini BI, Mekhail T, Triozzi P, Elson C, Nemec C et al (2007) A phase II trial of low-dose interleukin-2 (IL-2) and bevacizumab in patients with metastatic renal cell carcinoma (mRCC). J Clin Oncol, 2007 ASCO annual meeting proceedings part I, vol 25, no 18S (June 20 Supplement): 15586

17. Cooney MM, Garcia JBJ, Dreicer R, Beatty K, Mekhail T, Bukowski R et al (2007) A phase I study of bevacizumab in combination with sunitinib in advanced solid tumors. J Clin Oncol, 2007 ASCO annual meeting proceedings part I, vol 25, no 18S (June 20 Supplement): 15532

18. Merchan JR, Liu G, Fitch T, Picus J, Qin R, Pitot HC et al. (2007) Phase I/II trial of CCI-779 and bevacizumab in stage IV renal cell carcinoma: phase I safety and activity results. J Clin Oncol, 2007 ASCO annual meeting proceedings part I, vol 25, no 18S (June 20 Supplement):5034

19. Uemura H, Nakagawa Y, Yoshida K, Saga S, Yoshikawa K, Hirao $Y$ et al (1999) MN/CA IX/G250 as a potential target for immunotherapy of renal cell carcinomas. Br J Cancer 81(4):741746

20. Wykoff CC, Beasley NJ, Watson PH, Turner KJ, Pastorek J, Sibtain A et al (2000) Hypoxia-inducible expression of tumorassociated carbonic anhydrases. Cancer Res 60(24):7075-7083

21. Grabmaier K, Vissers JL, de Weijert MCA, Oosterwijk-Wakka JC, Van Bokhoven A, Brakenhoff RH et al (2000) Molecular cloning and immunogenicity of renal cell carcinoma-associated antigen G250. Int J Cancer 85(6):865-870

22. Grabmaier K, de Weijert AMC, Verhaegh GW, Schalken JA, Oosterwijk E (2004) Strict regulation of CAIX(G250/MN) by HIF-1alpha in clear cell renal cell carcinoma. Oncogene 23(33):5624-5631

23. Oosterwijk E, Bander NH, Divgi CR, Welt S, Wakka JC, Finn $\mathrm{RD}$ et al (1993) Antibody localization in human renal cell carcinoma: a phase I study of monoclonal antibody G250. J Clin Oncol 11(4):738-750

24. Divgi CR, Bander NH, Scott AM, O’Donoghue JA, Sgouros G, Welt $S$ et al (1998) Phase I/II radioimmunotherapy trial with iodine-131-labeled monoclonal antibody G250 in metastatic renal cell carcinoma. Clin Cancer Res 4(11):2729-2739

25. Steffens MG, Boerman OC, Oosterwijk-Wakka JC, Oosterhof GO, Witjes JA, Koenders EB et al (1997) Targeting of renal cell carcinoma with iodine-131-labeled chimeric monoclonal antibody G250. J Clin Oncol 15(4):1529-1537

26. Steffens MG, Boerman OC, de Mulder PH, Oyen WJ, Buijs WC, Witjes JA et al (1999) Phase I radioimmunotherapy of metastatic renal cell carcinoma with 131I-labeled chimeric monoclonal antibody G250. Clin Cancer Res 5(10 Suppl):3268s-3274s

27. Divgi CR, O’Donoghue JA, Welt S, O’Neel J, Finn R, Motzer RJ et al (2004) Phase I clinical trial with fractionated radioimmunotherapy using 131I-labeled chimeric G250 in metastatic renal cancer. J Nucl Med 45(8):1412-1421 
28. Brouwers AH, Mulders PF, de Mulder PH, van den Broek WJ, Buijs WC, Mala C et al (2005) Lack of efficacy of two consecutive treatments of radioimmunotherapy with $131 \mathrm{I}-\mathrm{cG} 250$ in patients with metastasized clear cell renal cell carcinoma. J Clin Oncol 23(27):6540-6548

29. Brouwers AH, van Eerd JE, Frielink C, Oosterwijk E, Oyen WJ, Corstens FH et al (2004) Optimization of radioimmunotherapy of renal cell carcinoma: labeling of monoclonal antibody cG250 with 131I, 90Y, 177Lu, or 186Re. J Nucl Med 45(2):327-337

30. Surfus JE, Hank JA, Oosterwijk E, Welt S, Lindstrom MJ, Albertini MR et al (1996) Anti-renal-cell carcinoma chimeric antibody G250 facilitates antibody-dependent cellular cytotoxicity with in vitro and in vivo interleukin-2-activated effectors. J Immunother Emphasis Tumor Immunol 19(3):184-191
31. Bleumer I, Knuth A, Oosterwijk E, Hofmann R, Varga Z, Lamers $C$ et al (2004) A phase II trial of chimeric monoclonal antibody G250 for advanced renal cell carcinoma patients. Br J Cancer 90(5):985-990

32. Bleumer I, Oosterwijk E, Oosterwijk-Wakka JC, Voller MC, Melchior S, Warnaar SO et al (2006) A clinical trial with chimeric monoclonal antibody WX-G250 and low dose interleukin-2 pulsing scheme for advanced renal cell carcinoma. J Urol 175(1):57-62

33. Divgi CR, Pandit-Taskar N, Jungbluth AA, Reuter VE, Gonen M, Ruan S et al (2007) Preoperative characterisation of clear-cell renal carcinoma using iodine-124-labelled antibody chimeric G250 (124I-cG250) and PET in patients with renal masses: a phase I trial. Lancet Oncol 8(4):304-310 